\title{
In Memoriam: Chang-Soon Koh, PhD, MD (1932 - 2012)
}

\author{
June-Key Chung
}

Published online: 9 November 2012

(C) Korean Society of Nuclear Medicine 2012

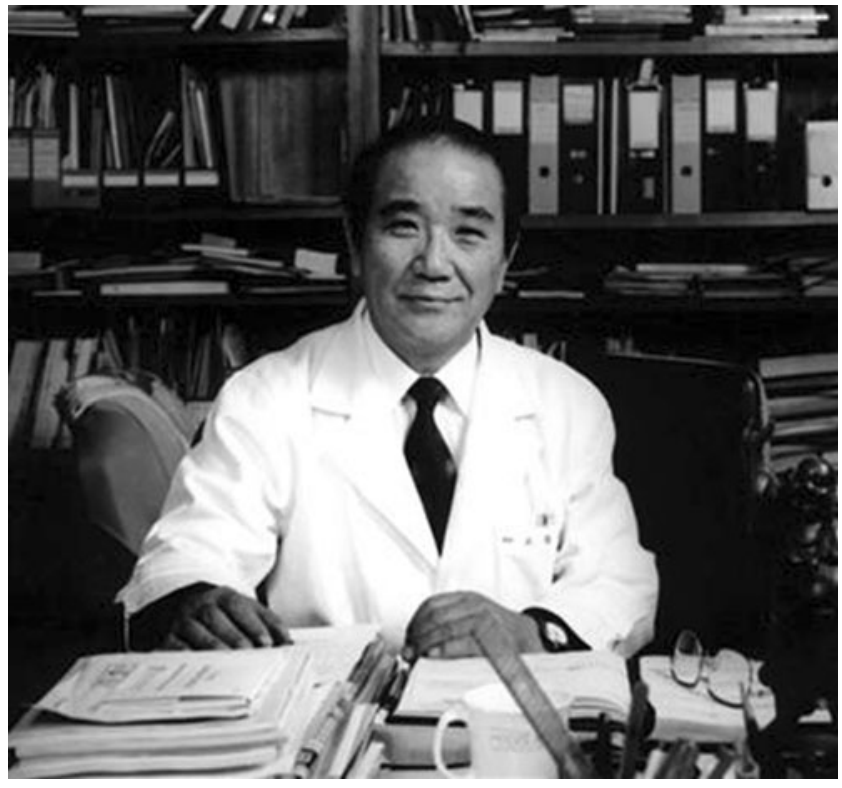

The late Professor Chang-Soon Koh was one of the people instrumental in establishing nuclear medicine as a firm and independent field of medicine. He also founded modern Korean thyroidology, in which radioiodine is used for diagnosis and treatment.

Chang-Soon Koh was born in the southern area of Korea on April 20, 1932. After finishing pre-medical courses at Seoul National University in 1953, he moved to Japan and graduated from Showa University School of Medicine in 1957. He then returned to Korea and started his residency at Seoul National University Hospital, where he became an

\section{J.-K. Chung $(\triangle)$}

Editor-in-Chief, Department of Nuclear Medicine,

Seoul National University College of Medicine,

101 Daehak-ro,

Jongno-gu, Seoul 110-744, Korea

e-mail: jkchung@snu.ac.kr internist in 1961. Five years later, under the supervision of Professor Munho Lee, he earned a $\mathrm{PhD}$ at Seoul National University College of Medicine.

Chang-Soon Koh played a key role in establishing the Institute of Radiation Medicine Research Center (currently known as the Korea Institute of Radiological \& Medical Sciences, KIRAMS) and was appointed to be the first director of the Radioisotope Clinic and Department of Nuclear Medicine from May 1963 to July 1969. Afterwards, he served as a professor at Seoul National University College of Medicine for 28 years. He was also appointed as the first director of the Department of Nuclear Medicine at Seoul National University Hospital (SNUH), and was the physician of the former Korean President, Mr. Young-Sam Kim.

In the academic field, Professor Koh devoted himself to the establishment of various divisions in medicine. At SNUH, he led a research group called "Dong-Won", from which arose diverse divisions of medicine, including nuclear medicine, endocrinology, nephrology, hematology, and infectiology. In particular, nuclear medicine was approved as a separate medical specialty by the Korean government in 1995. Many of Professor Koh's students and trainees, now part of the alumni group of Dong-Won, are considered to be very influential researchers and leaders in Korean medicine. Chang-Soon Koh was soft-spoken, kind, and thoughtful in his personal relationships, while in research and practice he loved challenges and insisted on professionalism, which formed the basis for the achievements of his group. His autobiography was given the title "Fifty Years of Challenge and Harmony" in accordance with to his character and his life.

Professor Koh served actively in various educational and academic societies. He served as the first dean and president of the College of Medical Sciences at Gachon University from 1998 to 2000 . He held consecutive posts as President of the Korean Society of Nuclear Medicine, Secretary 
General of the 3rd Asia and Oceania Congress of Nuclear Medicine, Vice-Chairman of the Asia and Oceania Thyroid Association, President of the Korean Radioisotope Association, Chairman of the Korean Endocrinology Society, and Chairman of the Korean Association of Internal Medicine. He played a leading role in founding the Korean Society of Medical and Biological Engineering and served as its president. He was also the first president of the Korean Society of Medical Informatics.

Chang-Soon Koh wrote more than 300 articles and 10 books, including the first edition of "Nuclear Medicine," published in 1992. In 2008, the third edition of "Nuclear Medicine," edited by June-Key Chung and Myung Chul Lee, was titled "Chang-Soon Koh's Nuclear Medicine" in honor of his contribution to nuclear medicine.
Personally, Professor Koh suffered three different cancers, starting in his 20s: colon, duodenal, and liver cancer. As a patient and physician, he demonstrated a strong will to overcome the cancers. Also, he got his optimistic, altruistic, and cooperative character from the experiences of striving to overcome various challenges, including the three cancers. He wrote a book, "Never Be Unbowed by Cancer," based on his personal experiences. Unfortunately, however, he passed away from recurrent liver cancer on August 6, 2012.

Professor Chang-Soon Koh lived a life dedicated to establishing and developing the challenging fields of medicine, especially nuclear medicine. He and his spirit of "Challenge and Harmony" will be remembered and respected in the history of Korean medicine. 